\title{
Recuperación del epitelio germinal masculino de ratones tratados con dosis única de Busulfán
}

\section{Male germinal epithelium recovery in mice treated with only dose of Busulfan}

\author{
Luis Guzmán¹, Rosmary López ${ }^{1}$, Guillermo Llerena², José Pino', Fernando Retuerto \\ Presentado: $07 / 04 / 2005$ \\ Aceptado: $\quad 12 / 07 / 2005$
}

\section{Resumen}

Busulfán es un agente alquilante bifuncional tipo-éster, que interfiere con la replicación del ADN. Dosis elevadas de este compuesto son aplicadas antes de los transplantes de médula ósea y de células germinales, sin embargo no han sido cuantificados el daño ni la recuperación del sistema reproductor. Para cuantificar la recuperación del efecto en la espermatogénesis, se usaron ratones de la cepa Balb C, a los que se les inyectó Busulfán intraperitonealmente, $40 \mathrm{mg} / \mathrm{kg}$ de peso corporal, y se evaluó el peso testicular y la concentración espermática en cola de epidídimo, a los 30, 54 y 72 días y se realizaron cortes histológicos de testículo. Los resultados fueron analizados con la prueba U Mann-Whitney $p>0.05$. A los 30 días el peso testicular, la concentración espermática y el diámetro de los túbulos seminíferos presentaron una drástica reducción del 77,8\%, 97,9\% y $34,3 \%$ respectivamente, comparados con el grupo control. A los 54 días, el peso testicular y el diámetro testicular muestran una recuperación del $70 \%$. A los 72 días, la recuperación es completa en los parámetros evaluados. Por lo tanto, Busulfán aplicado en una sola dosis afecta significativamente la espermatogénesis en el ratón y se logra la recuperación completa en dos ciclos espermáticos.

Palabras clave: Busulfán, ratón, espermatogénesis, recuperación.

\section{Abstract}

The DNA replication is disrupted by Busulfan which is a bifunctional alquilant as an ester agent. High dose of this compound are applied before transplants of bone marrow and germ cells. However quantification of the damage to the reproductive system and its recovery have not been established. The aim of this study was to quantify both spermatogenesis and spermiogenesis recovery in mice from damage caused by an injection of Busulfan. We used Balb C mice which were evaluated 30, 54 and 72 days after the intraperitoneal injection of $40 \mathrm{mg} / \mathrm{kg}$ body weight. We took the following variables: testicular weight, spermatic concentration in epididimus line and histological cuts to measure the diameter of the seminiferous tubules. Results were analyzed with the test $U$ Mann-Whitney $p>0.05$. By day 30, testicular weight, spermatic concentration and diameter of the seminiferous tubules were reduced to $77,8 \%, 97,9 \%$ and $34,3 \%$ respectively compared to the controls. At day 54 , testicular weight and diameter of the seminiferous tubules showed a recovery of $70 \%$. Recovery was complete by day 72. Therefore Busulfan applied in a sigle dose, affects significantly spermatogenesis and the completed recovery takes two spermatic cycles in mice.

Keywords: Busulfan, mouse, spermatogenesis, recovery.

\section{Introducción}

La espermatogénesis, es un proceso eficiente e importante para la continuación de las especies, una de sus características es que tiene una gran resistencia al daño. Este even-

\footnotetext{
${ }^{1}$ Facultad de Ciencias Biológicas. Universidad Nacional Mayor de San Marcos. Lima, Perú. Apartado 11-0058, Lima11, Perú.

E-mail José Pino: jpinog@unmsm.edu.pe

${ }^{2}$ Laboratorio de Reproducción Asistida y Genética del Instituto de Ginecología y Reproducción.
}

to tiene lugar en los túbulos seminíferos, que miden aproximadamente $200 \mu \mathrm{m}$ de diámetro en ratón y se estima que existen de 15 a 20 túbulos seminíferos en cada testículo, con una longitud total de 2 metros. Dentro de los túbulos seminíferos las células germinales están asociadas en una arquitectura altamente organizada y preestablecida. Existen tres principales fases en la espermatogénesis: En la primera, fase mitótica, la espermatogonia pro- 
lifera para incrementar en número y genera espermatocitos primarios. La segunda fase es la meiosis en la que los espermatocitos primarios experimentan la recombinación de la información genética y genera espermátides. La tercera fase es conocida como espermiogénesis, donde complicados procesos de diferenciación resultan en la morfología característica especie-específico (Monesi, 1982). Estas células en conjunto son llamadas células de la línea espermatogénica. En ratones un ciclo espermático completo dura 35 días (Franca, 1998). El proceso de espermatogénesis es muy productivo, donde teóricamente una espermatogonia es capaz de producir 4096 espermatozoides maduros en ratas (Russel, 1990). Durante el proceso de desarrollo, las células de la línea espermatogénica son mantenidas por las células de Sertoli, que responden a muchos factores como la hormona folículo estimulante (FSH), luteinizante (LH) y andrógenos (Monesi, 1982).

Busulfán, 1,4-butanodiol dimetanosulfonato, es un agente alquilante bifuncional tipo ester que reacciona con el nitrógeno en posición 7 de la guanina e interfiere con la replicación y transcripción del DNA, permitiendo uniones cruzadas de las cadenas de DNA. Además ejerce un mayor efecto mielosupresor en las células mieloides que el observado sobre las células linfoides. Esta relativa especificidad ha hecho que sea utilizado como agente antineoplásico. Altas dosis de este compuesto son usados en transplantes autólogos y alogénicos de médula ósea, causando una supresión severa de las células madres hematopoyéticas (Chan, 2000). El promedio de recuperación del número de neutrófilos luego de tratamiento con altas dosis empieza a los 19 días; la recuperación del número promedio de plaquetas es en el día 30 (Jopling \& Rosendaal, 2001). En el presente estudio se cuantificó la recuperación del daño causado por Busulfán en dosis única sobre la espermatogénesis en ratón.

\section{Material y métodos}

\section{Animales y tratamiento}

Se utilizaron ratones de la cepa Balb C, de cuatro semanas de edad, con un peso promedio entre 17 y $22 \mathrm{~g}$ al inicio del tratamiento. Los animales fueron mantenidos con un fotoperiodo de $14 \mathrm{~h}$ luz y $10 \mathrm{~h}$ oscuridad, alimentados con dieta balanceada para animales (Purina-Perú) y agua ad libitium. Se utilizaron 30 ratones, los cuales se dividieron en 3 grupos con su respectivo grupo control, los que se evaluaron a los 30, 54 y 72 días posterior a la inyección intraperitoneal de Busulfán (Myleran, Glaxo Wellcome Inc.) $40 \mathrm{mg} / \mathrm{kg}$ de peso corporal de ratón el cual fue diluido en proporción 1:1 con DMSO (Backer) y agua destilada (Ogawa, 1997). Posteriormente se sacrificaron por dislocación cervical analizándose los siguientes parámetros: peso testicular, concentración espermática en cola de epidídimo, y cortes histológicos de testículo de $8 \mu \mathrm{m}$ coloreados con Hematoxilina y Eosina Y (H\&E). El diámetro de los túbulos seminíferos fue determinado mediante un ocular micrométrico y se cuantificaron para ello 100 túbulos seminíferos por cada individuo (Gonzáles, 1992).

Tabla 1. Valores promedio de los parámetros analizados a los 30, 54 y 72 días después de administrada una dosis de Busulfán ( $40 \mathrm{mg} / \mathrm{kg}$ de peso corporal de ratón)

\begin{tabular}{lccc}
\hline & Peso Testicular $(\mathbf{g})$ & $\begin{array}{c}\text { Diámetro de Túbulo } \\
\text { Seminífero }(\boldsymbol{\mu m}) \\
\text { Media } \pm \text { DS }\end{array}$ & $\begin{array}{c}\text { Concentración } \\
\text { Espermática }(\mathrm{esp} / \mathrm{ml}) \\
\text { Media } \pm \text { DS }\end{array}$ \\
\hline Control * & $0,1332 \pm 0,0068$ & $184,47 \pm 21,26$ & $4,7 \times 10^{8} \pm 2,1 \times 10^{7}$ \\
30 días & $0,0300 \pm 0,0057^{\S}$ & $121,57 \pm 16,45^{\S}$ & $1,7 \times 10^{7} \pm 2,6 \times 10^{6 \S}$ \\
54 días & $0,0890 \pm 0,0059^{\S}$ & $186,57 \pm 38,55$ & $2,9 \times 10^{8} \pm 6,4 \times 10^{7 \S}$ \\
72 días & $0,1340 \pm 0,0087$ & $214,03 \pm 37,06$ & $3,5 \times 10^{8} \pm 4,3 \times 10^{7 \S}$ \\
\hline
\end{tabular}



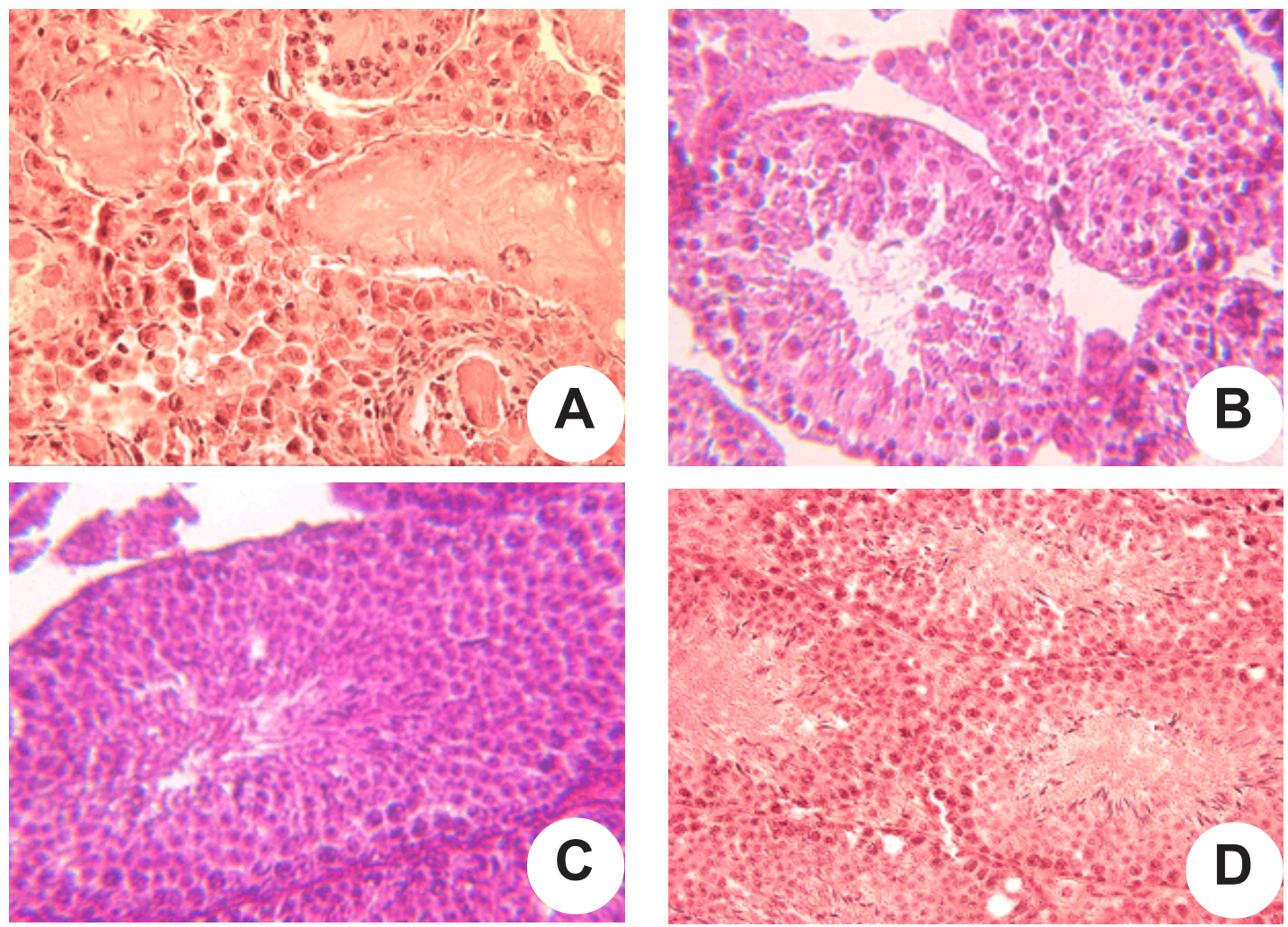

Figura 1. Cortes Histológicos coloreados con H\&E. (A) Morfología del Epitelio Germinal Masculino a 30 días post-inyección de Busulfán, 400X. (B) 54 días post-inyección, 250X. (C) Epitelio a los 72 días post-inyección, $630 \mathrm{X}$, demuestra una recuperación de la línea celular espermática respecto al control (D),400X.

\section{Análisis Estadístico}

Los datos fueron analizados con la prueba de U Mann-Whitney $\mathrm{p}>0,05$, usando el SPSS 11,0 para Windows. Los resultados son reportados con la media y desviación estándar(DS).

\section{Resultados}

A los 30 días de la aplicación de la dosis única de Busulfán se observa una reducción significativa en los parámetros cuantificados respecto al grupo control y también respecto a los días evaluados posteriormente. Los parámetros evaluados muestran una recuperación gradual a los 54 y 72 días (Tabla 1).

Del total de túbulos seminíferos analizados a los 30 días post-inyección, en el 83,7\% solo se encontraron espermatogonias del tipo A y B, en el 12,5\% se evidencia el desarrollo de la espermatogénesis hasta espermatocitos primarios y en el 3,8\% de túbulos no se observan espermatogonias. Las células mioides, ubicadas en la base de los túbulos seminíferos, se muestran intactas al igual que el número de células de Sertoli presentes en los túbulos seminíferos (Figura 1A). A los 54 días postinyección, en la morfología del epitelio germinal masculino se observa un desarrollo de los diferentes tipos celulares presentes (Figura 1B). A los 72 días post-inyección se evidencia una morfología similar respecto al grupo control (Figura 1C y 1D).

\section{Discusión}

Busulfán es absorbido por el tracto gastrointestinal, metabolizado exclusivamente en el hígado y excretado en la orina como ácido metanosulfónico. En altas dosis causa una severa supresión de las células de médula ósea, causando una prolongada mielosupresión afectando directamente las células con alto índice 
mitótico (Jopling y Rosendaal, 2001; Check et al., 2000). En nuestro estudio una simple dosis de Busulfán en ratones afectaría también a las espermatogonias en el sistema reproductor masculino. Sin embargo, en los datos encontrados este efecto se vería revertido. Para el caso de la concentración espermática en cola de epidídimo se demuestra una tendencia a la recuperación de manera progresiva, al comparar la evidencia morfológica con la histológica a los 72 días en testículo (ver figura $1 \mathrm{C}$ ) se evidencia una recuperación total respecto al control; sin embargo la concentración en la cola del epidídimo no es la esperada, probablemente debido a que los espermatozoides formados en el segundo ciclo espermático llegarían al epidídimo después de los 72 días.

En trabajos publicados usando como modelo ratas, las cuales son tratadas con dos dosis de Busulfán, las espermatogonias pueden sobrevivir interactuando con la lámina basal y la porción basal de las células de Sertoli experimentando divisiones simétricas y asimétricas y diferenciación asincrónica, resultando en el reestablecimiento de la espermatogénesis (Fang-Xu, 1998), estos resultados son concordantes con los obtenidos en nuestros estudio.

Por tanto, Busulfán aplicado en una sola dosis afecta significativamente la espermatogénesis en ratón, lográndose la recuperación completa en dos ciclos espermáticos.

\section{Literatura citada}

Chan, B. 2000 The Pharmacology of Peripheral Stem Cell Transplantation. P. Buchsel \& P. Kapustay, editors. In: Stem Cell Transplantation: A Clinical Textbook. Oncology Nursing Press, Inc. p 8.9-8.12.

Check M. L, Brown T., Check J. H. 2000 Recovery of spermatogenesis and successful conception after bone marrow transplant for acute leukaemia. Human Reprod 15:83-85.

Fang-Xu J. 1998 Behaviour of spermatogonia following recovery from busulfan treatment in the rat. Anat Embryol 198: 53-61.

Franca L., Ogawa T., Avarbock R., Brinster R. and Russell L. 1998 Germ cell genotype controls cell cycle during spermatogenesis in the rat. Biol Reprod 59:1371-1377.

Gonzáles G. F. 1992. Andrología fertilidad e infertilidad. Instituto de Investigaciones de la Altura Lima - Perú. Ediciones Instituto de Investigaciones de la Altura.

Jopling C, Rosendaal M. A. 2001 Cautionary tale: how to delete mouse haemopoietic stem cells with Busulphan. British J Haematol 113:970-974.

Monesi V. 1982. Espermatogénesis y espermatozoides. En: Austin CR, Short RV, editores. Células Germinales y Fertilización. Primera Edición. México: Ediciones Copilco. p. 49-88.

Ogawa T., Arechaga J., Varbock M. and Brinster R. 1997 Transplantation of testis germinal into muse seminiferous tubules. The International $\mathrm{J}$ Develop Biol 41:111-122

Russel L., Ettlin R., Hikim A. and Clegg E. 1990 Mammalian spermatogenesis. In: Histological and Histopathological Evaluation of the Testis. Clearwater. Cache River Press. 